\title{
ACADEMIC INTEGRITY TEACHER TRAINING: PREVENTIVE PEDAGOGICAL PRACTICES ON THE COURSE LEVEL
}

\author{
Sonja Bjelobaba
}

\begin{abstract}
More often than not, academic integrity as a discipline is defined by stating what it is not. Instead of focusing on what we want our students to do, we tell them that they should not cheat, plagiarize, collude, falsify or fabricate data, or engage in contract cheating. When defined in this way, academic integrity focuses on corrections of students' behaviour, detection, and punishment, still generally managing to avoid explaining to students what we want them to do instead.

Academic integrity can - and should - be defined in other ways, as a set of positive values or an agreement with ethical and professional principles, standards and practices that involve the whole institution.

Such a change in the definition inevitably changes our teaching of academic integrity: instead of correcting students' behaviour, different methods of the preventive and pedagogical promotion of academic integrity can be explored. One of them is an integration of academic integrity across the curriculum thus permeating all higher education. In order to achieve that, educational measures should not only be aimed at students, but to their teachers as well. In this paper a structure of an academic integrity teacher training workshop is presented with a focus on the integration of academic integrity in curriculum through constructive alignment and the examples of different preventive pedagogical practices.
\end{abstract}

\section{Introduction}

It is a frequently heard lament amongst teachers that "students should know that!" but it is not clear that this frequently voiced expectation is warranted. Students are generally not psychic, and particularly at a time in which students from vastly varied types and levels of academic preparation are admitted, such assumptions cannot be made. When it is essential that students obtain subject matter mastery, we make the essential information part of our curriculum; we do not assume that they already know what we want them to know. We do not demand that they find the information themselves or refer them to a web page or policy and consider the matter done, yet in the case of academic integrity, a sheet of paper - a policy, an honour code, a reminder that cheating and plagiarism will be punished or that they are expected to cite and reference correctly - is often the only "instruction" students receive on this complex problem.

Although the presence of policy documents and honour codes can have a positive effect on academic integrity (Bretag et al., 2011; McCabe, 1993; McCabe \& Treviño, 1993; McCabe et al., 2001), previous research has also shown that students rarely read policy documents and that their "understanding of plagiarism and how to avoid it requires much more than knowing what is in the policy documents" (Gullifer \& Tyson, 2014). Therefore, having a policy document and/or an honour code might not be enough. 
The enigma behind the sheet of paper pedagogics is the fact that academic integrity is a discipline that, much like apophatic theology (via negativa), is all too frequently defined by what it is not: it is not cheating on exams, it is not plagiarism, not colluding, not falsifying, not fabricating, not contract cheating. There is a correlation between the definition of academic integrity and the approaches to teaching and to dealing with it: when defined as what it is not, academic integrity focuses on prohibition and correction of students' behaviour. We focus on detection and punishment instead of teaching students what to do instead.

Academic integrity is not a divinity and thus can, and should, be defined in ways that focus on the positive approach of what it is. Glossary for Academic Integrity describes it as "Compliance with ethical and professional principles, standards and practices by individuals or institutions in education, research and scholarship" (Tauginienè et al., 2018: 7-8). International Center for Academic Integrity defines it in terms of six fundamental values: honesty, trust, fairness, respect, responsibility, and courage (International Centre for Academic Integrity, 2014).

Such a development of the definition with a focus on what academic integrity is and what values it consists of, leads to shifts in research, teaching and discussing academic integrity from methods that concentrate on the detection and punishment of misconduct toward focusing on the preventive and pedagogical promotion of academic integrity (Bertram Gallant, 2008; Bretag et al., 2014; Carroll \& Zetterling, 2009; Ferguson et al., 2007; Morris, 2016), and, finally, to developing a culture of honesty with clear standards and a holistic and systematic approach where the whole institution is included in the process (Bertram Gallant, 2016; Collins \& Amodeo, 2005; East, 2009; East \& Donnelly, 2012; Macdonald \& Carroll, 2006). Such a holistic approach contains a variety of methods and measures where policy and practice are aligned (Bretag et al., 2011) and where staff is highly engaged in the development of a shared understanding of academic integrity (Morris \& Carroll, 2016). Another aspect of such an approach is having adequate pedagogical measures: we cannot assume that students already know everything about academic integrity, we have to educate them.

\section{Teaching academic integrity}

In those cases, where educational measures regarding academic integrity exists, they are often aiming at students, teaching them basics of academic integrity such as how to reference properly and how to avoid plagiarism in general. These instructions are often done as short introductory courses, lectures, or seminars in the beginning of the educational process and normally facilitated by some specialist in academic writing or academic integrity such as librarians, or academic officers. The educational measures are often multidisciplinary presented and the discipline specific views on the academic integrity and academic writing are normally not considered, although such specifics can present a problem for a student when they start to write academic texts (Currie, 1993).

As approaches to academic integrity are most effective when they are customized to specific learning contexts, hence a positive, proactive and holistic approach towards academic integrity should be an integrated part of the curriculum. That means that a 
multidisciplinary course in academic integrity in the beginning of an education is not enough. In addition to such specialised introductory courses, the aim should also be to generate and practically implement the knowledge on academic integrity across the curriculum thus integrating academic integrity in all spheres of education and enabling a discipline specific approach. Such an implementation of knowledge in these fields requires a holistic approach including a professional development of teaching staff that encompasses different aspects of academic integrity and gives teachers tools to discuss these issues with their students.

\section{Teacher training workshops}

In this paper, I want to discuss the structure of the teacher training workshops I have been teaching at different higher education institutions in Sweden and abroad, as well as on various national and international conferences on campus or online. The aim of these teacher training workshops was to develop awareness and knowledge on how to integrate academic integrity as a part of courses and programmes by the usage of constructive alignment strategies (Biggs, 1996, 2003). In the hands on part of the workshop preventive pedagogical strategies were discussed in relation to particular disciplines and learning contexts.

The workshops were introduced with a discussion about what academic integrity is and how it could be defined, as well as a discussion on how teachers could foster academic integrity. The discussion also included the raising awareness of misconduct cases and equipping teaching staff to recognize and uncover the misconduct as well as the guidance on how to report it, how to use text-matching software, and on how to use policy documents and guidelines.

The workshops were given in two variants. In the first one, all the participants came from the same institution. In that case, the curriculum that was discussed were actual courses at the department and teaching groups had the opportunity to directly work with the actual course syllabuses, course content and assessment. In the second variant, the participants had a multidisciplinary background and were asked to work with a prearranged set of courses that they at a later stage could use as an inspiration for working on their own courses.

The pre-arranged set of courses was created in order to illustrate the progression during different stages of the learning process using Bloom's taxonomy (Anderson et al., 2001; Bloom et al., 1984) thus ensuring a systematic approach during different stages of higher education. The pre-arranged sets of courses that were discussed in groups included courses on different levels, in several disciplines and with various number of students such as:

- An introduction course in Computer Architecture, 30 students, 1st semester

- A course in Law, 120 students, 2nd semester

- A course in Biomedicine, Bachelor thesis writing, 21 students

- A PhD course in Russian linguistics, 5 students

Participants were divided into groups. Each group was asked to discuss one of the courses throughout the workshop, first within the group and later with all the other 
participants. The discussion was preferably facilitated in an active learning classroom in order to enhance participants' learning experiences and foster discussion (Park \& Choi, 2014) but in an online version facilitated in Zoom, combined with a pre-prepared Padlet was used as a discussion tool in order to enable active collaboration (Beitz, 2019; Garnham \& Betts, 2018).

The main part of the workshop was a practical approach to integrate academic integrity on the course level by using the constructive alignment (Biggs, 1996, 2003). In constructive alignment, the learning outcomes we intend students to learn are aligned with teaching activities and assessment tasks. It is apparent that the knowledge on academic integrity is currently most often not integrated through constructive alignment: an assignment that contains plagiarism or flawed source usage will be failed, so good source use is something that is examined. However, this assessment is usually not aligned with appropriate learning outcomes or learning activities as it is often assumed that students already know how to cite and paraphrase correctly. Thus, we are assessing something that is not a learning objective of the course and without the usage of any learning activities.

Students often do not perceive that the pedagogical measures on academic integrity that were given were enough (Bjelobaba et al. 2020, forthcoming). A proposition to use constructive alignment in teaching the source use was previously proposed by Pecorari (2013), however, the same principle could be used to teach other aspects of academic integrity as well. In order to do that, teachers should be equipped to develop learning outcomes, activities and assessment appropriate for their courses.

\section{Learning outcomes}

In a holistic approach, academic integrity should be clearly expressed as learning outcomes of a course. The first question workshop participants were challenged to consider therefore was: How can learning outcomes on academic integrity be developed in various courses to ensure the knowledge of source use, develop good research practice, and foster academic integrity in general?

There are several questions to be asked before choosing appropriate learning outcomes for a specific course (adapted from Pecorari, 2013): What do students need to know about academic integrity? What skills do they need to know to be able to do the assessments and task in the course? What do they already know and what they need help with? When is it appropriate to introduce that knowledge?

Courses on different levels will require different learning outcomes. Learning outcomes on academic integrity could be thematically categorized:

a) Knowledge on academic integrity.

After a course, a student should be able to:

- Articulate an understanding of what different forms of misconduct are (falsification, fabrication, plagiarism, deviations from good research practice)

- Be able to identify different forms of misconduct

- Know where the information and policy documents can be found

- Know the procedures used at the university for detecting and responding to misconduct 
b) Knowledge on academic writing.

After a course, a student should be able to:

- Identify bibliographical information in a text

- Understand how sources have been used in texts which signal them transparently

- Know what the function of referencing is

- Know how to cite and paraphrase correctly

- Be able to signal to the reader what is his/her own words and what is someone else's words

c) Knowledge on research integrity.

After a course, a student should be able to:

- Articulate an understanding of norms of good scientific research and research ethics

- Have the knowledge of and be able to apply the ethical standards in research

- Have the knowledge on the obtaining of permits from the relevant authorities (ethical approval, etc.)

- Have the knowledge of rules and regulations (Vancouver rules for co-authorship, etc.)

After presenting different types of learning outcomes, participants were asked to discuss and write learning outcomes that are appropriate for the course examined in their group and to take appropriate steps to ensure progression of these outcomes in accordance to Bloom's taxonomy (Anderson et al., 2001; Bloom et al., 1984). Afterwards, the learning outcomes in different courses were discussed with all workshop participants.

\section{Learning activities}

The second question workshop participants discussed was what tools and activities would be most adequate to align with the proposed learning outcomes. In order to help students build up knowledge of academic integrity, participants were asked to use appropriate learning activities. A range of such activities was presented.

Several examples of learning activities appropriate for developing academic integrity can be found on the Internet, in databases such as the website of European Network of Academic Integrity (http://www.academicintegrity.eu/wp/all-materials/) and workshop participants were encouraged to use those tools.

One important activity is fostering a discussion on academic integrity and the expectations on students: why do we ask our students to write in their own words, what do we mean when we ask them to produce an independent writing, and how do we view learning? Is learning something that occurs when a student is able to repeat a text word for word or do we see learning as a process that includes a student being able to process the knowledge and incorporate it with previous knowledge?

Learning outcomes that focus on the knowledge on academic integrity could require activities such as locating and discussing the policy documents and honour codes at the institution. 
If the focus of learning outcomes on the course is on academic integrity that is related to academic writing and proper source use, several activities can be done in order to actively work with the discipline specific scientific texts asking questions such as: "Why did the author reference in this way?" Students can be asked to make summaries of a particular text or paragraph, different aspects of referencing can be discussed and examples of wrong source use can be given, and different subtleties of plagiarism such as paraphrasing rules, referencing to the same author in one paragraph, translating citations, second source usage etc. could be discussed (See also Breen \& Maassen, 2005; Pecorari, 2013). Academic writing has different characteristics in different disciplines - showing examples of plagiarism and patchwriting (Howard, 1995) in a specific discipline is a form of enculturation that is necessary to fully master the academic literacy contract in that particular discipline.

Note taking skills that minimize risks of plagiarism such as using their own words as much as possible and using different colours for direct citation in order to avoid inadvertent plagiarism could be an appropriate learning activity.

Time management should be discussed in order to avoid what Bertram Gallant (2016: 987) calls the " 3 am syndrome" that occurs when students cheat because they run out of time, are exhausted or feel too much pressure.

After presenting different types of learning activities, participants were asked to choose the activities that are most appropriate to secure that the learning outcomes in the course they discussed were obtained. The chosen activities were later discussed with all participants.

\section{Assessment strategies}

The last question discussed in the workshop was: How can different practices in assessment design and practices affect academic integrity and make it harder and undesirable to engage in misconduct? Several assessment strategies were presented.

If the learning outcomes are focused on the knowledge on academic integrity such as the knowledge of the rules and where to obtain the information, that knowledge should be assessed. For learning outcomes that focus on academic writing, students can be examined on plagiarism, reference techniques, etc. In order to gain most pedagogical advantages, it is important to give feedback on referencing and to give students the opportunity to revise.

Another aspect of assessment strategies concerns the instructions on the exam. The instructions should be clear and comment aspects of academic integrity: if collaboration is not allowed, it should be stated, and students should always be reminded of the importance of referencing correctly. In the instructions it could be recalled that everything that is quoted / referenced should be listed in the literature list (but not everything that students have read).

Although the efficiency of the text-matching software can be discussed (Foltýnek et al., 2020; Weber-Wulff, 2015, 2019), the usage not only can spot texts from the Internet, but also increases the number of texts in the databases hence making it harder to reuse other students' texts. The software can also be used pedagogically to give feedback to learn about proper source-use (Davis \& Carroll, 2009). 
Designing the assessments is an important strategy in reducing misconduct and teachers training should discuss designing assessments that makes it hard to cheat: asking an outdated or generic question that can be googled in five minutes ("Write 2000 words on French revolution") will probably result in several copy-pasted Wikipedia entries. Instead, some thoughts should be put in the designing of the assessment and the assessment questions as original assessments will require an original answer (Carroll \& Appleton, 2001). Instead of finding an answer, the focus should be on making one by using individual experiences, contexts, or contemporary events or applying a specific theory on unusual set of cases. Other strategies include regularly changing old questions and exams, formative assessment that spreads assessment across the module, referring to contemporary events, making assessments relevant and stimulating (Bloxham \& Boyd, 2007).

As contract cheating - a form of academic dishonesty in which students pay others to complete their coursework (Clarke \& Lancaster, 2006) - is on the rise and present a serious threat to academic integrity (Bretag, 2019a; Newton, 2018), teacher training should discuss that problem. Previous research (Bretag et al., 2019b) has shown that there are no assessment types for which students reported a $0 \%$ likelihood of contract cheating, but that students did perceive four types of tasks that are least likely to prompt contract cheating: in-class tasks, personalised and unique tasks, vivas and reflections on practical placements. As there are no assessment types that are verified against contract cheating, an increased focus should be given the process by the usage of formative assessment thus making the process important by giving credits for it as well and not only for the end product (summative assessment). Meta-writing in form of a research diary or a logbook with descriptions of different stages of the project writing could also be used (such meta-writing can of course also can be purchased, but might make an additional cost that could deter some students from it).

An improvement of students' academic writing skills is highly connected to the improvement of academic integrity as inadvertent plagiarism can be reduced: the source of unintentional plagiarism and patchwriting is often based on the underdeveloped skills in academic writing (Sutherland-Smith, 2008). Hence, it is important that teachers take part in the writing process and ensure to not only get the last version but to give continuous feedback in order to develop students' writing skills (Court, 2014). Students should also show their activity during different process stages by using formative strategies including peer-assessment as research has shown that providing and receiving feedback from peers leads to improvements of writing performance (Huisman et al., 2018).

After discussing assessment strategies, workshop participants were asked to discuss what strategies could be useful in order to create an alignment with the learning outcomes and learning activities in the course they worked with.

\section{Conclusion}

In a holistic approach towards academic integrity, a proactive pedagogical approach is crucial. This pedagogical approach is not limited to education measures given in the scope of an introductory course, but should be integrated in all relevant courses within 
the tertiary education. In order to achieve that, teaching staff should be equipped through professional development programs and workshops. In order to give students a discipline specific introduction to academic integrity, it is necessary to equip teachers with methods and strategies to explore different preventive pedagogical practices on course level. After a teacher training workshop, a teacher should have the knowledge of what academic integrity is, how to inform his/her students, how to discover misconduct and where to report it, how to write the instructions in an assignment and how to, by means of constructive alignment, integrate academic integrity into all relevant courses given in the tertiary education.

\section{Literature}

Anderson, L. W., Krathwohl, D. R., \& Airasian, P. W. (2001). A Taxonomy for Learning, Teaching, and Assessing: A Revision of Bloom's Taxonomy of Educational Objectives. New York: Longman.

BeITZ, J. M. (2019). Padlet. Nurse Educator, 44(3), 169. doi: 10.1097/NNE.ooooooooooooo648.

Bertram Gallant, T. (2008). Academic Integrity in the Twenty-first Century: A Teaching and Learning Imperative. https://www.peterlang.com/view/9783631781593/xhtml/chapter1o.xhtml

Bertram Gallant, T. (2016). Leveraging Institutional Integrity for the Betterment of Education. In Bretag, T. (eds.) Handbook of Academic Integrity. Springer, Singapore, 979-994.

BigGs, J. (1996). Enhancing teaching through constructive alignment. Higher Education, 32(3), 347-364. https://doi.org/10.1007/BFoo138871

BIGGS, J. (2003). Aligning teaching and assessing to course objectives. Teaching and Learning in Higher Education: New Trends and Innovations, 2, 13-17.

Bjelobaba, S., Mumtaz, S., \& Fishman, T. (forthcoming 2020). The Challenge of Understanding Plagiarism: How do we know what we don't know?

Bloom, B. S., Krathwohl, D. R., \& Masia, B. S. (1984). Taxonomy of Educational Objectives. The Classification of Educational Goals: Cognitive Domain Handbook 1. New York: Longman

Bloxham, S., \& Boyd, P. (2007). Developing Effective Assessment in Higher Education: A Practical Guide. Maidenhead: McGraw-Hill International (UK) Ltd.

Breen, L., \& MAASSEN, M. (2005). Reducing the incidence of plagiarism in an undergraduate course: the role of education. Issues in Educational Research, 15(1), 1-16.

BretaG, T. (2019a). Contract cheating will erode trust in science. Nature, 574(7780), 599. doi:10.1038/d41586-019-03265-1

Bretag T., Harper R., Burton M., Ellis C., Newton P., Haeringen K., Saddiqui S., \& Rozenberg P. (2019b) Contract cheating and assessment design: exploring the relationship, Assessment E Evaluation in Higher Education, 44:5, 676-691, DOI: 10.1080/02602938.2018.1527892

Bretag, T., Mahmud, S., Wallace, M., Walker, R., James, C., Green, M., East, J., McGowan U., \& PATRIDGE, L. (2011). Core elements of exemplary academic integrity policy in Australian higher education. International Journal for Educational Integrity, 7(2). https://doi.org/10.21913/IJEI.v7i2.759

Bretag, T., Mahmud S., Wallace M., Walker R., McGowan U., East J., Green M., Partridge K., \& James C. (2014). Teach Us How to Do It Properly! An Australian Academic Integrity Student Survey. Studies in Higher Education, 39(7): 1150-1169. doi: 10.1080/03075079.2013.777406

CARroll, J., \& ZetTerling, C. M. (2009). Hjälp studenterna att undvika plagiering: Guiding students away from plagiarism. Stockholm: KTH Learning Lab. 
Carroll, J., \& Appleton J. (2001). Plagiarism: A Good Practice Guide. Accessed 25 May 2020. https://goo.gl/wUx2wG

Clarke, R., \& LANCASTER, T. (2006). Eliminating the successor to plagiarism: Identifying the usage of contract cheating sites, in Paper Presented at the Second International Plagiarism Conference. Gateshead.

Collins, M. E., \& AmodeO, M. (2005). Responding to Plagiarism in Schools of Social Work: Considerations and Recommendations. Journal of Social Work Education, 41(3), 527-543. https://doi.org/10.5175/JSWE.2005.200303131

COURT, K. (2014). Tutor feedback on draft essays: developing students' academic writing and subject knowledge. Journal of Further and Higher Education 38(3): 327-345.

Currie, P. (1993). Entering a disciplinary community: Conceptual activities required to write for one introductory university course, Journal of Second Language Writing, 2(2), 101-117, https://doi.org/10.1016/106o-3743(93)90012-R.

DAVIS, M., \& CARROLL, J. (2009). Formative feedback within plagiarism education: Is there a role for text-matching software? International Journal for Educational Integrity, 5(2), 58-70, DOI https://doi.org/10.21913/IJEI.v5i2.614

EAST, J. (2009). Aligning policy and practice: An approach to integrating academic integrity. Journal of Academic Language and Learning, 3(1), A38-A51.

EAST, J., \& Donnelly, L. (2012). Taking Responsibility for Academic Integrity: A collaborative teaching and learning design. Journal of University Teaching $\mathcal{E}$ Learning Practice, 9(3). Retrieved from http://ro.uow.edu.au/jutlp/volg/iss3/2

Ferguson, K., Masur, S., Olson, L., Ramirez, J., Robyn, E., \& Schmaling, K. (2007). Enhancing the Culture of Research Ethics on University Campuses. Journal of Academic Ethics, 5(2-4), 189-198. https://doi.org/10.1007/s10805-007-9033-9

Foltýnek, T., Dlabolová, D., Anohina-Naumeca, A., Razi, S., Kravjar, J., Kamzola, L., Guerrero-Dib, J., Çelik, O., \& Weber-Wulff, D. (2020). Testing of Support Tools for Plagiarism Detection. arXiv Publisher (Open Access): https://arxiv.org/pdf/2002.04279.pdf

Garnham, W., \& BetTs, T. (2018). The Padlet Project: Transforming student engagement in Foundation Year seminars. Compass: Journal of Learning and Teaching, 11(2). doi:https://doi.org/10.2110o/compass.v11i2.714

Gullifer, J., \& Tyson, G. (2014). Who has read the policy on plagiarism? Unpacking students' understanding of plagiarism. Studies in Higher Education, 39(7), 1202-1218.

Howard, R. M. (1995). Plagiarisms, Authorships, and the Academic Death Penalty. College English, 57(7), 788-806. doi:10.2307/378403

Huisman, B., SAAB, N., van Driel, J., \& VAN Den Broek, P. (2018). Peer feedback on academic writing: undergraduate students' peer feedback role, peer feedback perceptions and essay performance. Assessment \& Evaluation in Higher Education 43(6): 955-968.

International Centre for ACAdemic Integrity. (2014). Fundamental Values Project. Retrieved 31 May 2018, from https://academicintegrity.org/wp-content/uploads/2017/12/Fundamental-Values-2014.pdf

Macdonald, R., \& CARroll, J. (2006). Plagiarism - A complex issue requiring a holistic institutional approach. Assessment \& Evaluation in Higher Education, 31(2), 233-245. https://doi.org/10.1080/02602930500262536

McCABE, D. L. (1993). Faculty responses to academic dishonesty: The influence of student honor codes. Research in Higher Education, 34, 647-658.

McCabe, D. L., \& Treviño, L. K. (1993). Academic dishonesty: Honor codes and other contextual influence. Journal of Higher Education, 64, 522-538. 
McCabe, D. L., Treviño, L. K., \& Butterfield, K. D. (2001). Dishonesty in academic environments: The influence of peer reporting requirements. Journal of Higher Education, 72, 29-45

Morris, E. J., \& CARroll, J. (2016). Developing a Sustainable Holistic Institutional Approach: Dealing with Realities "on the Ground" When Implementing an Academic Integrity Policy. In BreTAG, T. (eds.) Handbook of Academic Integrity, 449-462. https://doi.org/10.1007/978-981-287-098-8_23

Morris, E. J. (2016) Academic Integrity: A Teaching and Learning Approach. In BretaG, T. (eds.) Handbook of Academic Integrity. Springer, Singapore, 409-412, https://doi-org.ezproxy.ub.gu.se/10.1007/978-981-287-098-8_11

Newton, P. (2018). How Common Is Commercial Contract Cheating in Higher Education and Is It Increasing? A Systematic Review. Frontiers in Education, 3, https://doi.org/10.3389/feduc.2018.00o67

PARK, E., \& CHOI, B. (2014). Transformation of classroom spaces: traditional versus active learning classroom in colleges. Higher Education (oo181560), 68(5), 749-771. https://doi-org.ezproxy.its.uu.se/10.1007/s10734-014-9742-o

Pecorari, D. (2013). Teaching to Avoid Plagiarism: How to Promote Good Source Use. Maidenhead: Open University Press.

Sutherland-Smith, W. (2008). Plagiarism, the Internet, and Student Learning: Improving Academic Integrity. Routledge.

Tauginienė, L., Gaižauskaitė, I., Glendinning, I., Kravjar, J., OJsteršek, M., Ribeiro, L., Odineca, T., Marino, F., Cosentino, M., \& Sivasubramaniam, S. (2018, January 31). Glossary for Academic Integrity. Retrieved 20 May 2020, from http://wWW.academicintegrity.eu/wp/wp-content/uploads/2018/o2/GLOSSARY_final.pdf

Weber-Wulff, D. (2015). Plagiarism Detection Software: Promises, Pitfalls, and Practices. In Bretag, T. (eds.) Handbook of Academic Integrity. Springer, Singapore, 625-638.

Weber-WulfF, D. (2019) Plagiarism detectors are a crutch, and a problem, Nature, 567, 435, doi: $10.1038 / \mathrm{d} 41586-019-00893-5$

\section{Author}

Sonja Bjelobaba; Center for Research Ethics and Bioethics \& Department of Modern Languages, Uppsala University, Sweden; e-mail: sonja.bjelobaba@crb.uu.se 